\title{
Too Crowded to Disclose! Exploring the Relationship Between Online Crowdedness and Self-Disclosure
}

\author{
HanByeol Stella Choi \\ KAIST College of Business \\ chb3@business.kaist.ac.kr \\ Junyeong Lee \\ USTC \\ junyeonglee@ustc.edu.cn
}

\author{
Chanhee Kwak \\ KAIST College of Business \\ kchhee@business.kaist.ac.kr \\ Heeseok Lee \\ KAIST College of Business \\ $\underline{\text { hsl@business.kaist.ac.kr }}$
}

\begin{abstract}
Nowadays, people communicate with many others online. Of the online sites, product review pages have become an important communication medium on which consumers share information about a product. Drawing upon this trend, we examined the factors that affect reviewers' self-disclosure behavior. Prior studies have found that privacy behaviors such as self-disclosure are affected by diverse contextual factors. In this study, we propose that online crowdedness is an important contextual factor for self-disclosure behavior. Using review data from the largest online apparel rental site in the U.S., we empirically explored the relationship between online crowdedness and self-disclosure behavior. The result shows that online crowdedness can discourage selfdisclosure behavior.
\end{abstract}

\section{Introduction}

Online shopping has become more than an alternative to the physical market, serving as the primary consumption model for many individuals. While buying and selling products, consumers can easily find reviews about products online. Many consumers generate reviews about a product or obtain valuable information from these reviews. Online review has thus become an important method of communication that has a salient effect on product sales. The primary purpose of online product reviews is to give feedback to retailors or provide information to potential buyers. Because online product reviews are proven to have a significant positive effect on product sales, the majority of online shopping malls utilize product review pages and attempt to attract consumers to write reviews by providing benefits to reviewers. Since the advent of online product reviews, their forms have changed. While early product reviews were constituted simply of written contents, recent product reviews contain dynamic contents, such as photos or videos.

The majority of prior studies on online product reviews have focused on the relationship between online product reviews and sales. As various types of contents are added to online product reviews, many studies have dealt with the ways in which different types of review contents affect product sales. Recently, scholars have been paying attention to the trustworthiness of reviews, rather than simply examining the relationship between each aspect of product reviews and sales. For example, reviewers' identity disclosure can have a significant positive relationship with product sales by enhancing the trustworthiness of the review [1]. In response to these findings, this study focuses on consumers' selfdisclosure behavior and attempts to discover the factors that lead to self-disclosure behavior in the context of online product review.

According to John, Acquisti, and Loewenstein [2], individuals tend to search for cues from the surrounding environment, since privacy is a domain where preference uncertainty is high. In this research stream, there has been a growing amount of research suggesting contextual factors that determine individuals' behavior. Self-disclosure behavior is also affected by many different contextual factors, such as social or physical environments [3-5]. Following this research stream, this study suggests a new contextual factor for consumer's self-disclosure behavior. Privacy behavior is affected by social or physical context; however, few studies have found a contextual factor that relates to both social and physical contexts. In order to close this research gap, 
we propose online crowdedness as a contextual factor, the definition of which contains both social and physical elements.

Using 223,119 online review data from a leading apparel rental site in the U.S., this study investigates the relationship between online crowdedness and consumers' self-disclosure behavior. Based on the analysis, the paper finds that online crowdedness is negatively related to self-disclosure, suggesting that individuals tend to conceal their private information rather that reveal it as the number of people on the Internet increases. This study is meaningful for literature on both crowdedness and privacy. From the perspective of crowdedness literature, this paper contributes by expanding the concept of crowdedness to an online context and by showing the shortcomings of a large volume of reviews. For privacy literature, this study contributes in three aspects: measuring self-disclosure via field data, finding a new contextual determinant of selfdisclosure behavior, and focusing on consumers' selfdisclosure behavior toward other consumers. Future research opportunities and limitations are also provided.

\section{Research background}

\subsection{Online reviews}

Consumers generate huge amounts of product reviews and obtain information from the reviews. Given this phenomenon, the online shopping mall has become an important communication medium. With the increase in the number and importance of online product reviews, they have become a topic of study for many researchers, and the majority of early studies emphasized the marketing power of product reviews [6]. These studies examined which factors of online product review have salient effects on product sales $[1,6]$.

While past studies focused on whether product review plays an important role in enhancing product sales, recent studies focus on consumers' motivation toward generating product reviews. Diverse factors such as reviewer characteristics [1], product types [7], previous review ratings [8], and product prices [9] have been found to affect individuals' motivation to write reviews [10].

Though online reviews primarily provide feedback on products and shopping experiences, they can contain not only information about the product or purchase experience but also the reviewer's private information. Many reviewers are voluntarily disclosing, or self-disclosing, their private information when writing reviews, though it is not mandatory, and this behavior entails potential privacy risks. For example, at Amazon.com, many reviewers disclose information concerning their identities, such as their real name or location. Additionally, on most of today's online apparel retail sites, consumers usually divulge their physical information, such as weight and height, when they leave reviews. Despite the increasing importance of this issue, selfdisclosure of private information has received relatively little attention in academia.

\subsection{Self-disclosure}

Self-disclosure refers to the act of revealing private information to others [11]. Self-disclosure has been of interest to scholars for several decades, especially in the context of human communications. Self-disclosure is one of the ways that humans interact with each other [12]. Drawing from communication privacy management (CPM) theory, disclosure plays a role as an axis of managing boundaries with others. Individuals thus balance their competing needs for privacy and disclosure by establishing or dismantling boundaries with others [13]. As online communication is increasing with the development of the Internet, self-disclosure studies have been expanded to include diverse online contexts, such as social network sites (SNS), online communities, e-commerce, or general Internet use.

This study aims to investigate consumers' behavior of disclosing private information when writing product reviews at online shopping malls. In this sense, this study follows the streams of selfdisclosure research in both an e-commerce context and a user generated content (UGC) context, since online product review is a type of UGC.

In self-disclosure studies in the e-commerce context, scholars have investigated underlying reasons for customers' decisions to disclose their private information to service providers or retailors at online shopping malls [14]. They suggested that online consumers make decisions to disclose their information to service providers based on risk-benefit analyses, website reputation, or situational demands such as the sole availability of the product [14]. In the case of disclosing information to other consumers on online commercial websites, consumers' identity disclosure has a significant and positive effect on product sales [1]. Therefore, it is worth investigating the underlying factors of consumers' information disclosing behavior when writing product reviews.

Individuals generate a massive amount of information, called UGC. UGCs include contents on diverse platforms, such as online communities, SNSs, and online product review sites [15]. In this context, 
many studies on self-disclosure have investigated the factors of self-disclosure on platforms such as online communities or SNSs. Based on theoretical models of information disclosure behavior (IDB), individuals' extroversion, perceived critical mass, perceived internet risk, privacy attitude, and privacy value serve as personal antecedents of self-disclosure behavior on SNSs [16, 17]. Privacy concern, perceived control over information, trust, privacy awareness, and user demographic characteristics were also found to affect self-disclosure [18-20]. In addition, given that SNSs or online communities are places where a "social" aspect is salient, individuals disclose their information to others for the purpose of developing social relationships [18, 20-22]. SNS users or members of online communities disclose their information to specific others who are acquainted with them, in exchange for the others' information disclosure [21, 22]. According to Green, Wilhelmsen, Wilmots, Dodd, and Quinn [23], self-disclosure is a way of developing and maintaining relationships both in the real world and on SNSs. Moreover, it was found that trusting and liking other members and the ability to predict their behaviors influence selfdisclosure [24-26].

Similarly, self-disclosure behavior has long been of interest to scholars in e-commerce and usergenerated contents literature. However, few studies have investigated online product reviewers' selfdisclosure behavior, though online product review is one form of UGCs that proliferates nowadays, as other UGCs of online communities or SNSs do. In this sense, this study aims to investigate the factors that affect individuals' behavior of disclosing private information when writing product reviews online.

\subsection{Context-dependent privacy behavior and crowdedness}

Privacy is a domain where preference uncertainty is salient, and individuals often search for cues from the surrounding environment when preference and behavioral uncertainty exist [2]. According to Hoofnagle and Jennifer [27], humans can be defined as privacy pragmatists, fundamentalists, or unconcerned, depending on time and place. Adopting the terminology of context-dependence to privacy behavior, individuals often rely on contextual cues when deciding their privacy behavior [12]. Following the research stream of context-dependent privacy behavior, several studies investigated diverse contextual factors affecting individuals' privacy behavior. For one, individuals' privacy behavior is usually affected by social contexts. For instance, we often tell secrets to close friends, but we sometimes disclose them to total strangers [3]. In Stutzman, Gross, and Acquisti's [4] longitudinal study on human behavior in a social network, it was found that disclosure behaviors are different toward friends and strangers. However, contextual cues that drive selfdisclosure are not merely limited to social contexts. Physical environment, such as temperature, lighting, or coziness, were also found to impact individuals' self-disclosure, even unconsciously [5]. Physical context also matters on the Internet that, individuals were more likely to disclose information on an online website with an unprofessional interface [2].

Crowdedness is defined as a situation in which a large group of people gather together such that there exists an increased chance of one's space being invaded [28]. Crowdedness often affects both the psychological state and behavior of individuals [2830]. Crowdedness used to be defined in an offline context. However, based on presence theories [31-33], individuals can also feel crowdedness in an online context.

According to social presence theory, individuals can perceive others even when real humans are not present [31]. They can perceive others as being present through mediated interfaces as well [32]. In other words, social presence can be adopted in a mediated environment; this is called mediated presence [33]. When presence theories are applied to online crowdedness, it becomes apparent that online crowdedness has the potential to influence an individual's psychological state and behavior, just as offline crowdedness does. As an online review page is a place where individuals can perceive the presence of others through existing reviews, social presence theory can be applied to a situation in which consumers write product reviews on such a page. Thus, a reviewer can sense the page to be crowded if he/she finds a large number of reviews on it.

\subsection{Online crowdedness and self-disclosure behavior}

Studies on crowdedness have shown several findings regarding the impact of crowdedness on individuals' psychological state and behavior. In selfdisclosure literature, it was found that individuals disclose more personal information when they perceive higher control [19]. Crowdedness is related to loss of control in behavioral, decisional, cognitive, and interpersonal aspects [30, 34, 35]. From the perspective of situational assessment, Maeng and Tanner [29] found that being in a crowd of others lead individuals to assess a greater potential threat because of the high level of uncertainty. A crowded situation causes individuals to respond defensively 
and to be hostile, risk sensitive, and preventionfocused [28], and prevention focus plays a moderating role in the relationship between the perceived risk of information disclosure and the behavioral intention to disclose personal information [36]. This implies prevention-focused individuals are less likely to disclose personal information as they perceive more risk in information disclosure. These findings suggest that crowdedness is negatively related to self-disclosure.

In contrast, individuals perceive themselves to be more anonymous and less unique in crowds [37]. When individuals perceive anonymity or that they are in situation in which they will receive less attention from others, they are less concerned about privacy risk [22]. Thus, we can also assume that individuals become less sensitive regarding the disclosure of private information on a more crowded review page. This study attempts to clarify the mixed evidence regarding the relationship between crowdedness and self-disclosure in online situations.

\section{Methods and data}

\subsection{Empirical context}

We collected data from one of the largest online apparel rental sites in the U.S. Since apparel is an experience good and requires the actual body size of users, individuals consider the reviews of others that include the previous users' physical information (e.g., height and weight), as well as purchase experiences. Our data contain 223,119 individual reviews on 3,211 designer dresses. Each review box includes the reviewer's name; whether the reviewer is a top contributor or not; the reviewer's information; review title; review content; review date; star-point; and photo. The reviewer has the right to skip writing or uploading contents included in the review box.

\subsection{Variables}

3.2.1 Dependent variable. In the reviewer information box, reviewers can include up to nine items, including the size worn; the overall fit of the dress; the occasion for which the dress was rented; the dress size usually worn by the reviewer; and the reviewer's height, age, bust size, body type, and weight. When writing a review, each reviewer can decide which information will be revealed on the page. We measured the dependent variable, selfdisclosure (Disclosure ${ }_{i j}$ ), by the number of pieces of information reviewer $i$ disclosed on the personal information page for the review of product $j$. The number of pieces of information disclosed ranges from 0 to 9 .

3.2.2. Independent variable. Following Shen, $\mathrm{Hu}$ and Ulmer [10], we measured crowdedness $\left(\right.$ Crowd $\left._{\mathrm{j}}\right)$ by the number of preexisting reviews for product $j$. Due to the high degree of skewness, we employed a natural $\log$ of crowdedness in the analysis model.

3.2.3. Control variables. The aim of this study is to examine e-commerce customers' reviewing behaviors regarding self-disclosure. Therefore, we considered the factors that impact online review behavior as control variables. According to prior studies, online review is a matter of decision-making, and online reviewers' behaviors are influenced by factors such as reviewers' characteristics [1], product characteristics [1, 10], and prior reviews [10]. Drawing upon these findings, we collected data on the product, reviewer, and prior review characteristics.

We collected reviews for all of the dresses on the website. Our data consist of product-specific characteristics, such as rental and retail price, designer name ( Designer $_{\mathrm{j}}$ ), operationalized by dummy variable, and the natural log of recommended order $\left(\log \left(\operatorname{Rank}_{\mathrm{j}}\right)\right)$ of product $j$, which represents the popularity of the product. In contrast to other online retailers, the website rents each dress to the consumer at a discounted price (rental price). We controlled for both the rental and retail price of product $j$ $\left(\right.$ Retail $_{\mathrm{j}}$, Rental $_{\mathrm{j}}$ ).

According to $\mathrm{Gao}, \mathrm{Hu}$, and Bose [38], reviewer ranking is important to the reviewer's review decision. Our website does not have a reviewer ranking system. Instead, the website gives a "top contributor" badge to devoted reviewers. Thus, we controlled for whether reviewer $i$ is a top contributor or not $\left(\mathrm{Top}_{\mathrm{i}}\right)$. We also collected the number of photos reviewer $i$ uploaded (NumPhoto $_{\mathrm{i}}$ ) and the length of his/her review (Length ${ }_{\mathrm{i}}$ ). These variables represent the reviewer's engagement, so we used the two as reviewer characteristics.

Our data include the recency $\left(\right.$ Recency $_{j}$ ) of the latest review and the average number of pieces of information disclosed among the 40 most recent reviews (AvgDisclosure ${ }_{j}$ ) on product $j$ 's review page. The reason that we calculated the average number of pieces of information disclosed among the 40 most recent reviews is that the website shows, at most, 40 reviews on one review page. 


\subsection{Analysis}

Figure 1. depicts our research model with key variables. We specify our empirical model of the following form, and we use ordinary least squares (OLS) to estimate the equation. Stata software is employed for the analysis.

$$
\begin{aligned}
\text { Disclosure }_{\mathrm{ij}}=\beta_{1} & \log \left(\text { Crowd }_{\mathrm{j}}\right)+\beta_{2} \log \left(\text { Rank }_{\mathrm{j}}\right) \\
& +\beta_{3} \text { Designer }_{\mathrm{j}}+\beta_{4} \text { Retail }_{\mathrm{j}} \\
& +\beta_{5} \text { Rental }_{\mathrm{j}}+\beta_{6} \text { Top }_{i} \\
& +\beta_{7} \text { NumPhoto }_{i}+\beta_{8} \text { Length }_{i} \\
& +\beta_{9} \text { Recency }_{\mathrm{j}} \\
& +\beta_{10} \text { AvgDisclosure }_{\mathrm{j}}+\varepsilon_{\mathrm{ij}}
\end{aligned}
$$

\begin{tabular}{|c|c|c|c|c|}
\hline Variable & Mean & Std. Dev & Min & Max \\
\hline \multicolumn{5}{|c|}{ Dependent Variable } \\
\hline Disclosure & 7.26 & 2.34 & 0 & 9 \\
\hline \multicolumn{5}{|c|}{ Independent Variable } \\
\hline $\log ($ Crowd $)$ & 4.53 & 1.44 & 0 & 8.18 \\
\hline \multicolumn{5}{|c|}{ Control Variables } \\
\hline Log(Rank) & 6.10 & 1.53 & 1 & 8.07 \\
\hline Designer & 63.94 & 42.53 & 1 & 144 \\
\hline Retail & 536.61 & 277.62 & 75 & 3,500 \\
\hline Rental & 57.56 & 28.02 & 30 & 400 \\
\hline Top & 0.57 & 0.50 & 0 & 1 \\
\hline
\end{tabular}

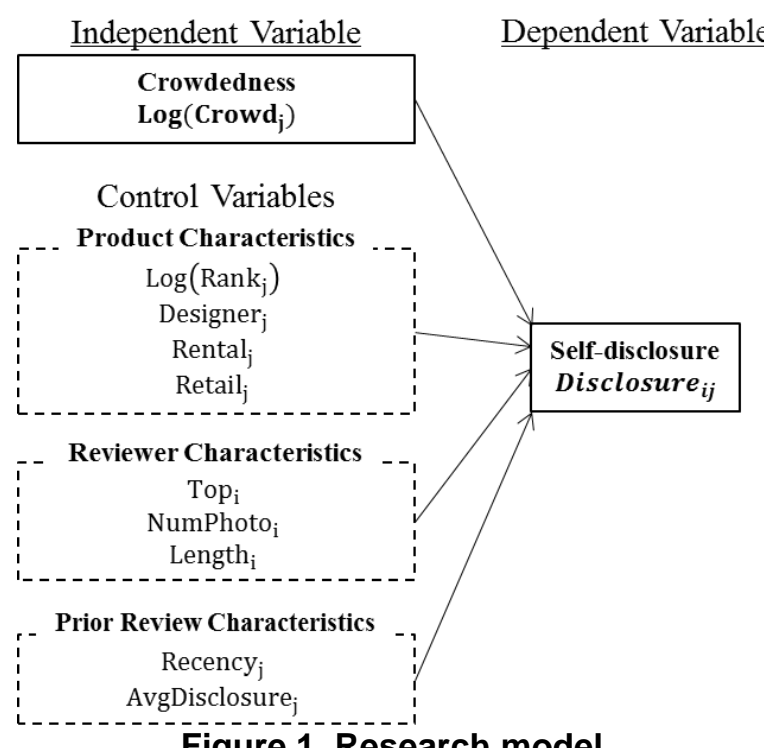

Figure 1. Research model

\section{Result}

Table 1. Descriptive statistics $(\mathrm{N}=\mathbf{2 2 3}, \mathbf{1 1 9})$

\begin{tabular}{|l|r|r|r|r|}
\hline NumPhoto & 0.65 & 0.64 & 0 & 4 \\
\hline Length & 293.87 & 217.37 & 0 & 2,808 \\
\hline Recency & 4.54 & 8.81 & 0 & 292 \\
\hline AvgDisclosure & 6.46 & 1.04 & 0 & 8 \\
\hline
\end{tabular}

Table 1 shows descriptive statistics of the variables, and Table 2 shows a correlation matrix. According to the correlation matrix, there do not exist any values that significantly exceed 0.7 , and all variance inflation factor (VIF) values of each variable are less than 3, suggesting that multicollinearity is not a serious concern in our analysis [39].

Table 3 summarizes our analysis results. The results suggest that all the variables in our model have a significant effect on the self-disclosure behavior of reviewers. Crowdedness, recommended order of the product, rental price, and recency are negatively related to self-disclosure. The result of crowdedness suggests that individuals tend to conceal their private information when there are more reviewers on the page. Additionally, the other results imply that if the recommended order of the product is high, meaning that the product is more visible, and the last review is more recent, individuals disclose more of their information. In contrast, the number of photos uploaded, length of review, and the average number of disclosures on the page are shown to have a positive relationship with self-disclosure. Additionally, individuals with top contributor badges are found to be more likely to disclose private information compared to those without top contributor badges. The results from the variables of top contributor, review length, and number of photos uploaded suggest that reviewers with higher engagement toward the website or review process are more likely to disclose their private information. The results regarding the average number of disclosures on the review page suggest that individuals follow the lead of others when disclosing their private information.

Since our dependent variable, the number of pieces of private information divulged by the consumer, is a count variable, we utilized a Poisson model to avoid potential violation of the distribution of errors from the ordinary least square model. Regarding all the variables, the results of the Poisson regression were consistent with those of the OLS model. Table 4 summarizes the analysis results of the Poisson regression. 
Table 2. Correlation matrix

\begin{tabular}{|l|l|l|l|l|l|l|l|l|l|l|}
\hline & $(1)$ & $(2)$ & $(3)$ & $(4)$ & $(5)$ & $(6)$ & $(7)$ & $(8)$ & $(9)$ & $(10)$ \\
\hline$(1)$ & 1 & & & & & & & & & \\
\hline$(2)$ & $-0.46^{*}$ & 1 & & & & & & & & \\
\hline$(3)$ & $-0.12^{*}$ & $0.18^{*}$ & 1 & & & & & & & \\
\hline$(4)$ & $0.11^{*}$ & $-0.18^{*}$ & $-0.16^{*}$ & 1 & & & & & & \\
\hline$(5)$ & $-0.11^{*}$ & $-0.09^{*}$ & $-0.11^{*}$ & $0.52^{*}$ & 1 & & & & & \\
\hline$(6)$ & $-0.16^{*}$ & $0.20^{*}$ & $0.10^{*}$ & $-0.10^{*}$ & $-0.07^{*}$ & 1 & & & & \\
\hline$(7)$ & $0.07^{*}$ & $-0.12^{*}$ & $-0.05^{*}$ & $0.08^{*}$ & $0.05^{*}$ & $-0.10^{*}$ & 1 & & & \\
\hline$(8)$ & 0.00 & $-0.07^{*}$ & $-0.04^{*}$ & $0.07^{*}$ & $0.05^{*}$ & -0.00 & $0.24^{*}$ & 1 & & \\
\hline$(9)$ & $-0.15^{*}$ & $0.24^{*}$ & $0.04^{*}$ & $0.03^{*}$ & -0.00 & $0.05^{*}$ & $-0.04^{*}$ & $-0.03^{*}$ & 1 & \\
\hline$(10)$ & $-0.03^{*}$ & $0.21^{*}$ & $0.06^{*}$ & -0.00 & $-0.14^{*}$ & $0.11^{*}$ & $-0.04^{*}$ & -0.00 & $0.07^{*}$ & 1 \\
\hline
\end{tabular}

Note. (1) $\log \left(\operatorname{Crowd}_{\mathrm{j}}\right)$, (2) Log(Rank ${ }_{\mathrm{j}}$ ), (3) Designer ${ }_{\mathrm{j}}$, (4) Retail $\mathrm{j}_{\mathrm{j}}$, (5) Rental $\mathrm{j}_{\mathrm{j}}$, (6) Top $\mathrm{p}_{\mathrm{i}}$, (7) NumPhoto $\mathrm{N}_{\mathrm{i}}$, (8) Length $_{i},(9)$ Recency $_{j},(10)$ AvgDisclosure $;$; ${ }^{*}<<0.001$

Table 3. OLS analysis results

\begin{tabular}{|c|c|}
\hline Independent Variable & $\begin{array}{c}\text { Disclosure }_{i j} \\
\text { (t-value) }\end{array}$ \\
\hline $\log \left(\operatorname{Crowd}_{j}\right)$ & $\begin{array}{l}-0.078^{* *} \\
(21.49)\end{array}$ \\
\hline $\log \left(\operatorname{Rank}_{\mathrm{j}}\right)$ & $\begin{array}{l}-0.029 * * \\
(-8.27)\end{array}$ \\
\hline Designer $_{j}$ & $\begin{array}{l}-0.000 * * \\
(-4.29)\end{array}$ \\
\hline Retail $_{j}$ & $\begin{array}{l}0.000^{* *} \\
(18.7)\end{array}$ \\
\hline Rental $_{j}$ & $\begin{array}{l}-0.004 * * \\
(-21.36)\end{array}$ \\
\hline Top $_{\mathrm{i}}$ & $\begin{array}{l}1.478^{* *} \\
(158.89)\end{array}$ \\
\hline NumPhoto $_{i}$ & $\begin{array}{l}0.053 * * \\
(7.27)\end{array}$ \\
\hline Length $_{\mathrm{i}}$ & $\begin{array}{l}0.001^{* *} \\
(47.72)\end{array}$ \\
\hline Recency $_{j}$ & $\begin{array}{l}-0.009 * * \\
(-15.9)\end{array}$ \\
\hline AvgDisclosure $_{j}$ & $\begin{array}{l}0.561^{* *} \\
(125.32) \\
\end{array}$ \\
\hline $\mathrm{N}$ & 223,119 \\
\hline R-squared & 0.1915 \\
\hline Adj R-squared & 0.1915 \\
\hline $\mathrm{F}$ & $\begin{array}{l}F_{(10,223,108)} \\
=5284.17\end{array}$ \\
\hline
\end{tabular}

Table 4. Poisson analysis results

\begin{tabular}{|c|c|}
\hline Independent Variable & $\begin{array}{c}\text { Disclosure }_{i j} \\
\text { (z-value) }\end{array}$ \\
\hline $\log \left(\right.$ Crowd $\left._{j}\right)$ & $\begin{array}{l}-0.009 * * \\
(-14.01)\end{array}$ \\
\hline $\log \left(\operatorname{Rank}_{\mathrm{j}}\right)$ & $\begin{array}{l}-0.004 * * \\
(-5.87)\end{array}$ \\
\hline Designer $_{j}$ & $\begin{array}{l}-0.000 * \\
(-3.26)\end{array}$ \\
\hline Retail $_{j}$ & $\begin{array}{l}0.000^{* *} \\
(13.04)\end{array}$ \\
\hline Rental $_{j}$ & $\begin{array}{l}-0.001^{* *} \\
(-14.91)\end{array}$ \\
\hline Top $_{\mathrm{i}}$ & $\begin{array}{l}0.207 * * \\
(124.03)\end{array}$ \\
\hline NumPhoto $_{i}$ & $\begin{array}{l}0.007 * * \\
(5.69)\end{array}$ \\
\hline Length $_{i}$ & $\begin{array}{l}0.000 * * \\
(37.09)\end{array}$ \\
\hline Recency $_{j}$ & $\begin{array}{l}-0.001 * * \\
(-12.19)\end{array}$ \\
\hline AvgDisclosure $_{j}$ & $\begin{array}{l}0.082 * * \\
(97.56)\end{array}$ \\
\hline $\mathrm{N}$ & 223,119 \\
\hline Log likelihood & -510579.46 \\
\hline Pseudo R-squared & 0.0312 \\
\hline
\end{tabular}

\section{Conclusion}

\subsection{Summary}

In this study, we examine how online crowdedness and individuals' self-disclosure 
behavior are related in the context of online product reviews. We find that online crowdedness has a significant negative effect on consumers' selfdisclosure behavior. The result suggests that as individuals become conservative and prevention focused, they tend to conceal their private information toward others $[28,36]$. Other than crowdedness, recommended order of the product, rental price, and review recency are also found to be negatively related to self-disclosure behavior, whereas the top contributor variable, number of photos uploaded, review length, and average number of disclosures were positively related to selfdisclosure.

\subsection{Implications}

Our findings provide important implications for theory and practice. The theoretical implications lie in both crowdedness and self-disclosure literature. This study contributes to crowdedness studies with the following insights. First, this study provides the insight that individual behaviors are affected not only by offline crowdedness but also by online crowdedness. Though there have been numerous studies investigating the effect of crowdedness on individuals' behavior, the research context has been limited to the offline environment. Applying crowdedness in an online review context, this study expands the domain of crowdedness to an online environment. Second, this study reveals the paradox of a large volume of product review. This study examines the relationship between online crowdedness, measured by review volume, and consumers' self-disclosure behavior. According to traditional beliefs, a large volume of reviews used to be considered as a good indicator for sales. However, this study suggests that, sometimes, a large number of reviews has a negative effect on other customers' decisions when reviewers tend to provide less information. Disclosing less information means reviewers do not provide detailed information in online reviews, and the trustworthiness of each review might be threatened.

From the perspective of self-disclosure studies, this study contributes to prior research as follows. First, using online review data, this study measured the actual amount of information disclosed by consumers. Prior studies based on survey data alone showed individuals' intentions regarding selfdisclosure. Our analysis result is more likely to reveal actual self-disclosing behavior of individuals. Second, by suggesting online crowdedness as the antecedent for affecting individuals' self-disclosure behavior, this study contributes to finding a new contextual factor that is of recent interest to scholars. Finally, by looking at consumer's self-disclosure behavior in an online review context, our study provides implications for self-disclosure literature. Previous studies on self-disclosure behavior in an e-commerce context were limited to consumer's self-disclosure toward service providers (e.g., disclosing bank account information when a transaction is made or other private information when registering for a site). Applying our findings in other contexts, further study can enlarge our understanding of self-disclosure behaviors.

Our analysis results have a few clear practical implications. First, the result from recommended order suggests that when review pages of popular products have a higher chance of being seen, individuals tend to disclose their information. This is consistent with Shen, Hu, and Ulmer's [10] argument that reviewers strategically write reviews to get attention from other consumers. Reviewers choose to provide more detailed information for the reviews on popular products' review pages because there is a higher chance for the review to be seen. Second, in the case of recency, the result means that the more recent the last review, the more likely individuals are to disclose more information. A plausible explanation is that individuals disclose more information on a page with more recent reviews because recent reviews can provide feelings of intimacy. Third, the variable for top contributor, the number of photos uploaded, and review length reflect the engagement level of reviewer. The fact that these variables have a positive relationship with self-disclosure implies that consumers with high engagement are more likely to disclose their private information. Fourth, the result from the average number of disclosure variable can be explained as conformity behavior, the act of changing one's behavior in a way that matches others' responses [40]. The result reveals that conformity behavior can be noted in the context of information disclosure on an online product review page.

\subsection{Future research opportunities}

The demographic characteristics of reviewers in our study can be biased, since most of the reviewers on our website are women. As our data context only offers outfits for women, we could not examine gender effect. However, as self-disclosure behavior might differ by gender, future studies can consider this aspect.

According to prior studies, self-disclosure can be characterized by two dimensions, breadth and depth. Self-disclosure breadth refers to the amount of information disclosed and depth refers to the degree 
of intimacy in revealing information [19]. However, the current study only examines the breadth of selfdisclosure because of the lack of a theoretical standard for deciding the privateness of information included in our data. A further investigation is of interest to create a robust standard of information depth and to examine how external factors influence individuals to disclose even the most private of information.

\section{References}

[1] Forman, C., Ghose, A., and Wiesenfeld, B., "Examining the Relationship between Reviews and Sales: The Role of Reviewer Identity Disclosure in Electronic Markets", Information Systems Research, 19(3), 2008, pp. 291-313.

[2] John, L.K., Acquisti, A., and Loewenstein, G., "Strangers on a Plane: Context-Dependent Willingness to Divulge Sensitive Information", Journal of Consumer Research, 37(5), 2011, pp. 858-873.

[3] Kelley, H.H., The Social Psychology of Groups, Transaction Publishers, 1967.

[4] Stutzman, F., Gross, R., and Acquisti, A., "Silent Listeners: The Evolution of Privacy and Disclosure on Facebook", Journal of Privacy and Confidentiality, 4(2), 2013, pp. 2.

[5] Altman, I., "The Environment and Social Behavior: Privacy, Personal Space, Territory, and Crowding", 1975.

[6] Chevalier, J.A., and Mayzlin, D., "The Effect of Word of Mouth on Sales: Online Book Reviews", Journal of Marketing Research, 43(3), 2006, pp. 345-354.

[7] Mudambi, S.M., and Schuff, D., "What Makes a Helpful Review? A Study of Customer Reviews on Amazon. Com", MIS Quarterly, 34(1), 2010, pp.185-200.

[8] Moe, W.W., and Trusov, M., "The Value of Social Dynamics in Online Product Ratings Forums", Journal of Marketing Research, 48(3), 2011, pp. 444-456.

[9] Li, X., and Hitt, L.M., "Price Effects in Online Product Reviews: An Analytical Model and Empirical Analysis", MIS Quarterly, 34(4), 2010, pp. 809-831.

[10] Shen, W., Hu, Y.J., and Ulmer, J.R., "Competing for Attention: An Empirical Study of Online Reviewers' Strategic Behavior", MIS Quarterly, 39(3), 2015, pp. 683696.

[11] Joinson, A.N., "Self-Disclosure in Computer-Mediated Communication: The Role of Self-Awareness and Visual Anonymity", European Journal of Social Psychology, 31(2), 2001, pp. 177-192.
[12] Acquisti, A., Brandimarte, L., and Loewenstein, G., "Privacy and Human Behavior in the Age of Information", Science, 347(6221), 2015, pp. 509-514.

[13] Petronio, S., Boundary of Privacy: Dialectics of Disclosure, State University of New York Press, Albany, 2002.

[14] Metzger, M.J., "Communication Privacy Management in Electronic Commerce", Journal of Computer-Mediated Communication, 12(2), 2007, pp. 335-361.

[15] Dhar, V., and Chang, E.A., "Does Chatter Matter? The Impact of User-Generated Content on Music Sales", Journal of Interactive Marketing, 23(4), 2009, pp. 300-307.

[16] Chen, R., "Living a Private Life in Public Social Networks: An Exploration of Member Self-Disclosure", Decision Support Systems, 55(3), 2013, pp. 661-668.

[17] Tow, W.N.-F.H., Dell, P., and Venable, J., "Understanding Information Disclosure Behaviour in Australian Facebook Users", Journal of Information Technology, 25(2), 2010, pp. 126-136.

[18] Jiang, Z., Heng, C.S., and Choi, B.C., "Research Note-Privacy Concerns and Privacy-Protective Behavior in Synchronous Online Social Interactions", Information Systems Research, 24(3), 2013, pp. 579-595.

[19] Taddei, S., and Contena, B., "Privacy, Trust and Control: Which Relationships with Online SelfDisclosure?", Computers in Human Behavior, 29, 2013, pp. 821-826.

[20] Zlatolas, L.N., Welzer, T., Heričko, M., and Hölbl, M., "Privacy Antecedents for Sns Self-Disclosure: The Case of Facebook", Computers in Human Behavior, 45, 2015, pp. 158-167.

[21] Barak, A., and Gluck-Ofri, O., "Degree and Reciprocity of Self-Disclosure in Online Forums", CyberPsychology \& Behavior, 10(3), 2007, pp. 407-417.

[22] Posey, C., Lowry, P.B., Roberts, T.L., and Ellis, T.S., "Proposing the Online Community Self-Disclosure Model: The Case of Working Professionals in France and the Uk Who Use Online Communities", European Journal of Information Systems, 19(2), 2010, pp. 181-195.

[23] Green, T., Wilhelmsen, T., Wilmots, E., Dodd, B., and Quinn, S., "Social Anxiety, Attributes of Online Communication and Self-Disclosure across Private and Public Facebook Communication", Computers in Human Behavior, 58, 2016, pp. 206-213.

[24] Sheldon, P., "' I'll Poke You. You'll Poke Me!" SelfDisclosure, Social Attraction, Predictability and Trust as Important Predictors of Facebook Relationships", 
Cyberpsychology: Journal of Psychosocial Research on Cyberspace, 3(2), 2009.

[25] Sheldon, P., and Pecchioni, L., "Comparing Relationships among Self-Disclosure, Social Attraction, Predictability and Trust in Exclusive Facebook and Exclusive Face-to-Face Relationships", American Communication Journal, 16(2), 2014, pp. 1-14.

[26] Steijn, W.M., and Schouten, A.P., "Information Sharing and Relationships on Social Networking Sites", Cyberpsychology, Behavior, and Social Networking, 16(8), 2013, pp. 582-587.

[27] Hoofnagle, C.J., and Jennifer, M., "Urban. 2014.“Alan Westin's Privacy Homo Economicus.”", Wake Forest Law Review, 49(1), 2014, pp. 261-317.

[28] Maeng, A., Tanner, R.J., and Soman, D., "Conservative When Crowded: Social Crowding and Consumer Choice", Journal of Marketing Research, 50(6), 2013, pp. 739-752.

[29] Maeng, A., and Tanner, R.J., "Construing in a Crowd: The Effects of Social Crowding on Mental Construal", Journal of Experimental Social Psychology, 49(6), 2013, pp. 1084-1088.

[30] Schmidt, D.E., and Keating, J.P., "Human Crowding and Personal Control: An Integration of the Research", Psychological Bulletin, 86(4), 1979, pp. 680.

[31] Lee, K.M., "Presence, Explicated", Communication theory, 14(1), 2004, pp. 27-50.

[32] Lim, J.S., Hwang, Y., Kim, S., and Biocca, F.A., "How Social Media Engagement Leads to Sports Channel Loyalty: Mediating Roles of Social Presence and Channel Commitment", Computers in Human Behavior, 46, 2015, pp. 158-167.

[33] Short, J., Williams, E., and Christie, B., "The Social Psychology of Telecommunications", John Wiley \& Sons, London, 1976.

[34] Baum, A., Aiello, J.R., and Calesnick, L.E., "Crowding and Personal Control: Social Density and the Development of Learned Helplessness", Journal of Personality and Social Psychology, 36(9), 1978, pp. 1000.

[35] Hui, M.K., and Bateson, J.E., "Perceived Control and the Effects of Crowding and Consumer Choice on the Service Experience", Journal of Consumer Research, 18(2), 1991, pp. 174-184.

[36] Brakemeier, H., Widjaja, T., and Buxmann, P., "Calculating with Different Goals in Mind-the Moderating Role of the Regulatory Focus in the Privacy Calculus", Darmstadt Technical University, Department of Business
Administration, Economics and Law, Institute for Business Studies (BWL), 2016.

[37] Andrews, M., Luo, X., Fang, Z., and Ghose, A., "Mobile Ad Effectiveness: Hyper-Contextual Targeting with Crowdedness", Marketing Science, 35(2), 2015, pp. 218-233.

[38] Gao, B., Hu, N., and Bose, I., "Follow the Herd or Be Myself? An Analysis of Consistency in Behavior of Reviewers and Helpfulness of Their Reviews", Decision Support Systems, 95, 2017, pp. 1-11.

[39] Diamantopoulos, A., "The Error Term in Formative Measurement Models: Interpretation and Modeling Implications", Journal of Modelling in Management, 1(1), 2006, pp. 7-17.

[40] Cialdini, R.B., and Goldstein, N.J., "Social Influence: Compliance and Conformity", Annual Review of Psychology, 55, 2004, pp. 591-621. 